\title{
BOdY SURFACE AND CORE TEMPERATURES OF HibERNATING BLACK BEARS
}

\author{
H.J. HARLOW $\downarrow$ T. LOHUIS $\downarrow$ DEPARTMENT OF ZOOLOGY AND PHYSIOLOGY \\ UNIVERSITY OF WYOMING \ LARAMIE
}

\author{
R.C. ANDERSON-SPRECHER $\downarrow$ DEPARTMENT OF STATISTICS \\ UNIVERSITY OF WYOMING
}

\section{T. D.I. BECK $\uparrow$ COLORADO DIVISION OF WILDLIFE FORT COLLINS}

\begin{abstract}
$\uparrow$ ABSTRACT:
Temperature data sensors were placed in the abdominal cavity, on the neck and outside the den of 5 black bears (Ursus americanus) during early winter and removed at the end of winter prior to the bear's leaving their den. Abdominal temperature remained around $35^{\circ}-36^{\circ} \mathrm{C}$ and did not appear to exhibit circadian rhythmicity. Neck surface temperature of bears, however, demonstrated elevated spikes from $2^{\circ}$ to $30^{\circ} \mathrm{C}$ about 4 times each day. We suggest that bears engage in bouts of muscular activity during the winter denning period to retain muscle strength and may vasodilate the skin to dissipate the heat rather than elevate their core body temperature and arouse from torpor.
\end{abstract}

\section{$\uparrow \quad$ INTRODUCTION:}

Hibernating bears enter shallow torpor with a body temperature decrease of only $5-7^{\circ} \mathrm{C}$ (Craighead et al., 1976; Folk, 1967; Hissa et al., 1994; Hissa, 1997; Watt et al., 1981) and are believed not to engage in bouts of arousal (Hissa et al., 1994; Nelson et al. 1973; Nelson, 1980). However, the body temperature profile of free-ranging bears in their natural dens during the winter has not been well documented. For example it is not known if naturally hibernating bears maintain a relatively constant state of hypothermia throughout the winter without periods of increased activity and associated heat production. It is also not known if free ranging bears exhibit a circadian rhythm in their body temperature that free runs during total darkness typically found in their dens.

If bears do not undergo periodic arousal bouts and muscular activity is minimal during the winter denning period, a loss in muscle strength typical of muscle disuse atrophy would be expected (Hortobagyi et al., 2000; Widrick et al., 1998). On the contrary, recent studies have shown that bears, during prolonged confinement in their dens do not lose the amount of skeletal muscle integrity (Tinker et al, 1998) and strength (Harlow et al 2001) predicted for animals experiencing similar periods of inactivity. Heat from skeletal muscle contractions can be conserved by bears and measured as a change in core body temperature or it can be dissipated as transepithelial flow down a thermal gradient and measured as an alteration in skin or fur temperature. An additional objective of this study is to measure deep core and surface temperature of hibernating bears as well as ambient temperature near the den in order to determine the fate of heat production and assess the amount of activity exhibited by 
overwintering bears in their natural winter environment.

\section{$\downarrow$ METHODS}

Adult bears $(n=5)$ were captured in southeastern Wyoming and fitted with radiotelemetry collars (Advanced Telemetry Systems, 150-160 MHz range). These bears were tracked to their dens in November and again in March. Bears were anesthetized with Telazol $(7.0 \mathrm{mg} / \mathrm{kg})$ administered by a spring activated jab stick. A $3 \mathrm{~cm}$ long abdominal incision was made along the linea alba and a sterile StowAway Tidbit temperature logger (accuracy $+0.2^{\circ} \mathrm{C}$ resolution $0.16^{\circ} \mathrm{C}$ ) was stitched into the muscle wall of the peritoneal cavity.

A second temperature sensor was secured to the bear's neck tracking collar so the thermocouple bead laid close to the fur in order to monitor fluctuating temperatures emanating from the area around the bear's neck and head. A third sensor was attached to trees within the vicinity of the dens and not exposed to direct sunlight to provide a daily air temperature profile.

Bears were revisited and anesthetized during late February and March to remove the temperature sensor from the neck collar and abdomen and retrieve the ambient temperature sensor. Data from the three temperature loggers for each bear were downloaded into a software program and expressed in Excel. Peaks in skin temperature above baseline were visually identified and quantified as being high amplitude (10$\left.30^{\circ} \mathrm{C}\right)$ or medium amplitude $\left(5-10^{\circ} \mathrm{C}\right)$ with the remainder being temperature spikes less than $5^{\circ} \mathrm{C}$. The presence of daily patterns in ambient air, body and collar temperature of bears was tested using spectral analysis. The presence of a correlative effect of outside temperature on the collar temperature and core temperature of bears was tested using second order autoregressive error regression.

\section{$\downarrow \quad$ RESULTS}

Temperature loggers were programmed to read from the body cavity, neck collar and outside ambient air for varied time intervals between December and March. We report data on an expanded scale from 5 bears during the month of February that represents their mid-winter hibernation period prior to transmitter removal or disturbance. Two bears held a core body temperature within $33^{\circ}$ - $34^{\circ} \mathrm{C}$, two bears within $34^{\circ}-35^{\circ} \mathrm{C}$ and one between $35.5^{\circ}$ and $36.5^{\circ} \mathrm{C}$ during the midwinter monitoring period (see Figure 1 as an example profile). No bears appeared to exhibit a daily rhythm of body temperature changes (Figure 1). There was a distinct daily ambient air temperature change within the vicinity of the den. The collar temperature sensors of all bears recorded bouts of elevated temperatures that were independent from the diel ambient air fluctuations (Figure 1) and did not correlate with a change in core body temperature (Figure 1). There was an average of 4.1 bouts of elevated temperature per day, half of which were of either high amplitude $\left(10^{\circ}-30^{\circ} \mathrm{C}\right)$ or medium amplitude $\left(5^{\circ}-10^{\circ} \mathrm{C}\right)$ changes with the remainder being temperature spikes $5^{\circ} \mathrm{C}$ or less (Table 1). The collar temperature of three bears rose to or elevated above their core body temperature on several occasions as represented in Figures 1, 2.

Figure 1. Temperatures recorded every 10 minutes from the abdominal cavity, neck surface and outside ambient air for a representative bear within its natural dens during the month of February

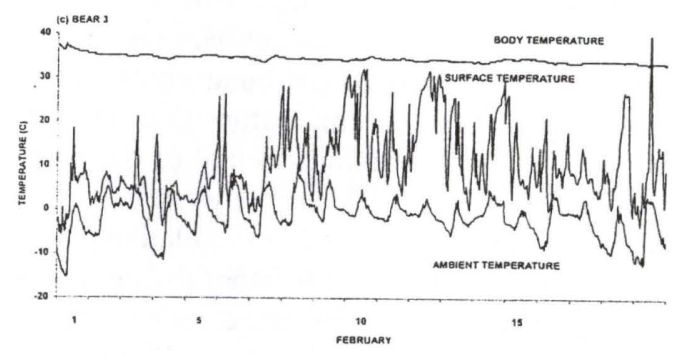

Table I: Mean number of temperature spikes for 5 bears each day during the month of February.Spikes are categorized as mild $\left(2^{\circ}-5^{\circ} \mathrm{C}\right)$, medium $\left(5^{\circ}-10^{\circ} \mathrm{C}\right)$ and large $\left(10^{\circ}-20^{\circ} \mathrm{C}\right)$. Number in parenthesis represents SEM.

TEMPERATURE NUMBER OF TEMPERATURE

$\begin{array}{ll}\text { SPIKES } & \text { SPIKES PER DAY }\end{array}$

\begin{tabular}{|c|c|c|c|c|c|c|}
\hline & $\# 301$ & $\# 385$ & $\# 399$ & $\# 477$ & $\# 743$ & AVERAGE \\
\hline $\operatorname{MILD}\left(2-5^{4} \mathrm{C}\right)$ & $2.5(0.3)$ & $3.1(0.3)$ & $1.1(0.3)$ & $4.1(0.3)$ & $1.8(0.3)$ & $2.5(0.2)$ \\
\hline MEDIUM $\left(5-10^{\circ} \mathrm{C}\right)$ & $0.7(0.2)$ & $0.7(0.3)$ & $1.1(0.3)$ & $\begin{array}{c}.05(0.01 \\
)\end{array}$ & $2.4(0.3)$ & $1.0(0.1)$ \\
\hline LARGE $\left(10-20^{\prime \prime} \mathrm{C}\right)$ & $0.5(0.2)$ & $0.2(0.1)$ & $2.5(0.3)$ & $0.0(0.0)$ & $0.3(0.1)$ & $0.7(0.1)$ \\
\hline $\begin{array}{l}\text { TOTAL SPIKES PER } \\
\text { DAY }\end{array}$ & $3.6(0.2)$ & $4.0(0.2)$ & $4.7(0.2)$ & $4.1(0.1)$ & $4.4(1.0)$ & $4.1(0.1)$ \\
\hline
\end{tabular}

Figure 2. Abdominal and neck surface temperature of a representative bear over four days in early February.

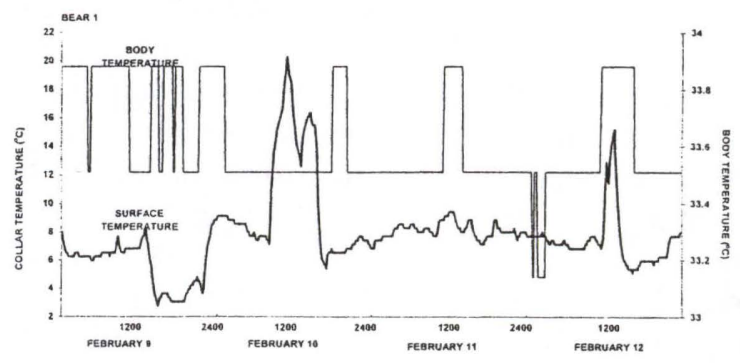




\section{DISCUSSION}

No studies have been conducted to monitor the core body temperature of bears in their natural den throughout the winter season to determine the constancy of torpor and if free running circadian temperature rhythms occur. The extent of hypothermia $\left(4^{\circ}-5^{\circ} \mathrm{C}\right)$ below the normal body temperature by 5 free living bears in the present study was similar to that reported on captive, hibernating bears (Hissa et al., 1994; Hissa, 1997) without an arousal bout to the euthermic state. However, unlike the Hissa et al., 1997 study, the abdominal temperature of our 5 hibernating bears in their natural dens remained relatively constant suggesting the absence of an endogenous, circadian body temperature rhythm.

The absence of rhythmic fluctuations in core temperature is not necessarily reflective of the absence of muscular activity bouts and consequent heat production by these five free-living, hibernating bears. We believe the temperature changes recorded in the collar sensor represent radiant heat loss across the skin and fur as a result of muscular contractions. The fact that the core body temperature in bears does not show concomitant alterations to that of the collar temperature spikes representing body surface heat loss implies that bears are vasodilating their peripheral tissue to dissipate heat rather than retain it. This would explain the temperature spikes of the collar above that of the body core. If vigorous muscular activity results in localized heat production, vasodilation could shunt that heat to the surface, making the surface temperature higher than the abdominal core temperature.

The bear's unparalleled strategy of shallow torpor with episodic muscular activity would be instrumental in maintaining a condition of relative muscle strength and responsiveness. These two characteristics are vital for bears to react to external disturbances since their size often precludes complete concealment characteristic of small hibernators such as ground squirrels (Linnel et al., 2000). Because of their relative exposure during the winter, bears are subject to potential predation by wolves, mountain lions and even coyotes while hibernating. Retention of muscle strength through a combination of protein conservation and muscle stimulation, would provide a definite survival advantage for overwintering bears by enhanced capacity for a flight or fight response. Our previous and ongoing work on muscle morphology supports the hypothesis that overwintering, inactive bears retain muscle integrity.

\section{Literature Cited}

Craighead, J.J., J.R. Varney, F.C. Craighead and J.S. Sumner. 1976. Telemetry experiments with hibernating black bears. In Bears-Their Biology and Management (Edited by Pelton, M.R., J.W. Lentfer and E.G. Folk) pp 357-371. Morges, Switzerland.

Folk, G.F. 1967. P hysiological observations of subarctic bears under winter den conditions. In Mammal Hibernation (Edited by Fisher, K.C., A.R. Dawe, C.P. Lyman, E. Schonbum and F.E. Smith) Vol III pp 75-85. Elsevier, New York.

Harlow, H.J., T. Lohuis, T.D.I. Beck and P.A. Iaizzo. 2001. Muscle strength in overwintering bears. Nature 409: 997.

Hissa, R., J. Siekkinen, E. Hohtola, S. Saarela, A. Hakala, and J. Pudas. 1994. Seasonal patterns in the physiology of the European brown bear (Ursus arctos arctos) in Finland. Comparative Biochemistry and Physiology A 109(3). 781791.

Hissa, R. 1997. Physiology of the European brown bear (Ursus arctos arctos). Annales Zoologici Fennici. 34(4): 267-287.

Hortobagyi, T., L. Dempsey, D. Fraser, D. Zheng, G. Hamilton, J. Lambert and L. Dohm. 2000. Changes in muscle strength, muscle fiber size and myofibrillar gene expression after immobilization and retraining in humans. Journal of Physiology 524 (1): 293-304.

Linnell, J.D., J.E. Swenson, R. Andersen and B. Barnes. 2000. How vulnerable are denning bears to disturbance? Wildlife Society Bulletin 28(2): 400-413.

Nelson, R.A. 1980. Protein and fat metabolism in hibernating bears. Federation Proceedings 39: 2955-2958.

Nelson, R.A., H.W. Wahner, J.D. Jones, R.D. Ellefson and P.E. Zollman. 1973. Metabolism of bears before, and after winter sleep. American Journal of Physiology 224: 491-496. 
Tinker, D.B., H.J. Harlow and T.D.I. Beck 1998. Protein use and muscle-fiber changes in freeranging, hibernating black bears. Physiological Zoology 71(4): 414-424.

Watt, P.D., N.A. Oritsland, C. Jonkel and K. Ronald. 1981. Mammalian hibernation and the oxygen consumption of a denning black bear (Ursus americanas). Comparative Biochemistry and Physiology 69: 121-123.

Widrick, J.J., K.M. Norenberg, J.G. Romatowski, C.A. Blaser, M. Karhanek, J. Sherwood, S.W. Trappe, T.A. Trappe, D.L. Costill and R.H. Fitts. 1998. Force-velocity-power and force$\mathrm{pCa}$ relationships of human soleus fibers after 17 days of bed rest. Journal of Applied Physiology 85(5): 1949-1956. 